\title{
VISOKOŠKOLSKO OBRAZOVANJE IZ UGLA KONCEPTA LJUDSKOG KAPITALA ${ }^{* *}$
}

Apstrakt: U okviru proučavanja odnosa pedagogije i drugih nauka tradicionalno primarni značaj pridaje se odnosu pedagogije prema filozofiji, sociologiji, psihologiji i antropologiji kao predmetno i metodološki bliskim naukama. U radu se polazi od stava da u savremenim uslovima ne treba da se zanemari ni odnos pedagogije i ekonomije. Savremeno obrazovanje suočava se sa brojnim izazovima i promenama koje su prvenstveno uslovljene procesom globalizacije, kao i uticajima neoliberalne ideologije. Kao cilj rada postavlja se sagledavanje značaja teorije ljudskog kapitala kao jednog od teorijskih pristupa u okviru proučavanja globalizacije obrazovanja, a koji sve više dobija na značaju, prvenstveno u oblasti visokoškolskog obrazovanja. Međutim, pridavanje sve većeg značaja ekonomskim aspektima obrazovanja rezultiralo je brojnim kritikama. Kao zaključak rada ističe se da se obrazovanju u celini, a posebno visokoškolskom obrazovanju pristupa sve više iz ugla ekonomskih aspekata. Iako je ovaj proces neizbežan prvenstveno kao posledica globalizacije, u cilju očuvanja humanističke dimenzije obrazovanja značajno je razumevanje i brojnih izazova i promena sa kojima se suočava proces visokoškolskog obrazovanja.

Ključne reči: ekonomija obrazovanja, visokoškolsko obrazovanje, ljudski kapital.

\section{UVOD}

Činjenica je da koncepti globalizacije i ljudskog kapitala nisu primarno pedagoški termini. Iako globalizacija i ljudski kapital imaju značajne implikacije na društveno-humanističke nauke u celini, ti fenomeni

\footnotetext{
* Maja Bosanac, maja.bosanac@ff.uns.ac.rs

** Rad je nastao u okviru projekta Pedagoški pluralizam kao osnova strategije obrazovanja (179036) koji finansira Ministarstvo prosvete, nauke i tehnološkog razvoja.
} 
dominantno pripadaju ekonomskom domenu. Međutim, njihovi uticaji imaju velik značaj za proces obrazovanja, prvenstveno kada je reč o visokom obrazovanju. U tom kontekstu, potrebno je imati u vidu da sve nauke proučavaju samo različite pojave, različite manifestacije jedinstvene materijalne, društvene i psihičke stvarnosti, zakonitosti koje u njoj vladaju. Kada se govori o povezanosti nauka, pa tako i o povezanosti pedagogije s drugim naukama, nije cilj da se odredi koja je nauka važnija, koja je na višem nivou na lestvici u sistemu nauka, koja je nezavisnija ili koja ima veću društvenu i naučnu ulogu, već se radi o tome s kojim se naukama pedagogija može povezati kako bi mogla brže i uspešnije dalje da se razvija (Grandić, 2007). Značajna je i činjenica da i u okviru iste nauke postoji različita povezanost $\mathrm{s}$ drugim naukama unutar različitih disciplina.

Konkretno, kada je reč o visokoškolskoj pedagogiji sve više na značaju dobijaju relacije između pedagogije i ekonomije. Otuda je bitno da se sagledaju značajni aspekti povezanosti visokoškolske pedagogije sa globalizacijom kao širom osnovom u okviru koje bi se detaljnije analizirao koncept ljudskog kapitala. Kada je reč o ekonomiji obrazovanja, Kutlača i saradnici (2011: 18) naglašavaju da se u Srbiji ona svodi isključivo na diskusiju o pitanju finansiranja. Strateški cilj za koji se izjasnilo Ministarstvo prosvete, nauke i tehnološkog razvoja je povećanje procenta stanovništva $\mathrm{s}$ visokim obrazovanjem (Službeni glasnik RS, 107/2012), i u tom cilju finansiranje visokog obrazovanja dobija na značaju. Iako odnos između pedagogije i ekonomije karakterišu i mnoge kontroverze i izazovi, njihovo prožimanje je neminovnost današnjeg vremena u okvirima nove ekonomije zasnovane na znanju, na neoliberalnoj ideologiji i na potrebi povezivanja univerziteta sa tržištem. Pri tome, mnogi autori danas (Bok, 2005; 
Liessmann, 2008) kritikuju tržišnu logiku univerziteta, što takođe predstavlja značajan pokazatelj sve dominantnijeg uticaja tržišne logike na visokoškolsko obrazovanje.

Ukoliko se prati istorijski razvoj pedagogije, neophodno je da se posmatra njen odnos prema filozofiji u čijem okrilju je ta nauka i nastala. Međutim, pod uticajem globalizacije, disciplinu visokoškolske pedagogije karakteriše veće uplitanje ekonomskih aspekata (koji su oduvek bili prisutni, ali je njihov značaj danas sve istaknutiji). Kao što se u literaturi ističe (Grandić, 2007: 184), nijedna pedagogija ne može da se izgradi kao celovita nauka ukoliko ne pođe od odgovora na pitanja: šta je čovek, kakva je njegova priroda i suština, kakva je njegova misija i sudbina, šta je smisao ljudske egzistencije, rada i života, šta je to društvo, šta je to zajednica kojoj čovek pripada? Iako je ovde reč o filozofskim pitanjima, odgovor na njih u savremenom društvu nije sveobuhvatan ukoliko ne uključuje i ekonomske aspekte. Takođe, povezanost ekonomije i visokoškolskog obrazovanja ogleda se i u sve češćim zahtevima za uslužnim delatnostima u okviru obrazovanja. Prema savremenim pristupima ističe se da ekonomija predstavlja bilo koji poseban sistem organizacije za proizvodnju, razmenu, raspodelu i potrošnju dobara i usluga kojima ljudi zadovoljavaju svoje potrebe (Puljić, 2001). U tom okviru i ekonomija se u značajnoj meri bavi zadovoljenjem ljudskih želja i potreba u određenoj zajednici.

\section{GLOBALIZACIJA, OBRAZOVANJE I TEORIJA LJUDSKOG KAPITALA}

U doba globalizacije, koju karakteriše sve izraženija međunarodna razmena ideja i praksi, međunarodne organizacije imaju veoma značajnu ulogu u uspostavljanju globalnog obrazovnog diskursa. To podrazumeva 
činjenicu da globalni akteri imaju vrlo sličan pogled na to kako treba da izgleda obrazovanje u informatičkom dobu, te vrlo često promovišu slične principe obrazovanja i razvoja koji treba da budu prihvaćeni u većini zemalja (Spasenović, 2019: 78). U tom okviruvažnu ulogu za obrazovanje imaju Organizacija za ekonomsku saradnju i razvoj (OECD), kao i Svetska banka. Uticaj OECD-a na obrazovne politike ogleda se u zahtevu posvećenosti tržišnoj ekonomiji i liberalnoj demokratiji, dok se najznačajniji uticaj na obrazovanje ostvaruje u okviru jednog od najpoznatijih i najuticajnijih međunarodnih testiranja - PISA istraživanja koja su dominantno usmerena ka uticaju na upravljanje obrazovnim sistemima i na obrazovnu politiku u okviru „moći brojeva” i „moći komparacije” (Popović, 2014, prema: Spasenović, 2019: 84). Značajno je i to da Svetska banka svoj program u oblasti obrazovanja zasniva na postavkama teorije ljudskog kapitala.

Pri tome $\mathrm{u}$ ekonomijama zasnovanim na znanju obrazovanje predstavlja značajnu komponentu. Jasno je da je za produktivnu ekonomiju visoki životni standard i ekonomski prosperitet bitan ljudski, ali i fizički, kapital i odgovarajuće ekonomsko okruženje (slobodno tržište, sloboda izbora obrazovanja). Bez obrazovanih i obučenih radnika, kao i bez menadžera fizički kapital pak ne može biti u potpunosti iskorišćen (Šućur, 2008). Dalje je, u kontekstu razmatranja merenja ljudskog kapitala, važno odrediti odnos između procesa globalizacije koji utiče na visokoškolsko obrazovanje i razvoja ljudskog kapitala. $\mathrm{Na}$ ovom mestu neće biti reči o mikroekonomskim i makroekonomskim aspektima merenja ljudskog kapitala, budući da je to ekonomska tematika, već o pristupu merenju ljudskog kapitala zasnovanog na obrazovanju, koji ima direktne pedagoške implikacije. 
Analizi globalizacije moguće je pristupiti iz različitih uglova. Uobičajeno se ukazuje na to da globalizacija zahvata tri glavne dimenzije: 1) ekonomsku, koja se primarno odnosi na finansijsku integraciju sveta, 2) političku, koja se tiče oblikovanja međudržavnih integracija i 3) kulturnu, koja obuhvata globalnu etiku, a koja se određuje kao sistem zajedničkih vrednosti (Pastuović, 1999, prema: Milutinović, 2008). Svaka od ovih dimenzija ima snažne implikacije na obrazovanje i učenje. Kada je reč o uticaju globalnih procesa na oblast obrazovanja najveći doprinos daju discipline kao što su sociologija obrazovanja, antropologija obrazovanja, ekonomija obrazovanja i slično. Jedan od pregleda različitih teorija i pristupa globalizaciji ukazuje upravo na one teorijske pristupe koji su važni s aspekta proučavanja globalizacije u obrazovanju, a to su: teorija ljudskog kapitala, teorija modernizacije, teorije zavisnosti svetskog sistema, teorija svetske (globalne) kulture i teorija globalnog kapitalizma (Portnoi, 2016, prema: Spasenović, 2019: 60).

U literaturi se (Dubravčić, 2007: 30) ističe da glavni pokretač ekonomskog razvoja predstavlja kapital, koji se, uprkos različitim definicijama, najjednostavnije može shvatiti kao akumulisana fizička i finansijska imovina koja se koristi za proizvodnju. $U$ faktore razvoja uključuje se i ljudski kapital (ulaganje u obrazovanje i zdravlje ljudi u cilju povećanja njihovih proizvodnih sposobnosti) i tehnologija kao kodifikovano ljudsko znanje o proizvodnji. Pod ljudskim kapitalom misli se na znanja, veštine, kompetencije i sva svojstva pojedinca koja olakšavaju stvaranje ličnog, društvenog i ekonomskog blagostanja (OECD, 2002, prema: Pastuović, 2012). Pod svojstvima koja nisu znanja i veštine podrazumevaju se urođene sposobnosti i zdravlje. Determinante od kojih zavisi kvalitet tako 
definisanog ljudskog kapitala pojedinca obuhvataju: 1) obrazovanje usavršavanje na radnom mestu i neformalno učenje, 2) urođene osobine intelektualne i psihomotorne sposobnosti, sklonost bolestima, odnosno zdravlje, kao i 3) porodica, društvena sredina i ostali sredinski činioci (OECD, 2002, prema: Pastuović, 2012). Prema teoriji ljudskog kapitala, obrazovanje direktno utiče na povećanje produktivnosti pojedinca, a time i na njegov dohodak tokom radnog veka. U tom okviru ljudski kapital poistovećuje se sa fizičkim kapitalom, a njegovo sticanje podrazumeva trošak u sadašnjosti, ali korist u budućnosti (Bečić, 2014).

Izvesna analogija između fizičkog i ljudskog kapitala pojavljuje se, pre svega, u upotrebi pojmova amortizacije i održavanja (Dubravčić, 2007: 33). Kod ljudi dodatnu ulogu imaju biološki faktori, budući da pri kraju životnog veka čovek ne može koristiti akumulisani kapital znanja i veština jer on bespovratno odlazi s njim. Bez obzira na vrstu i kvalitet ljudskog kapitala koji je ugrađen u čoveka njegova amortizacija povezana je sa životnim ciklusom, pa se kasnije stečena znanja moraju brže amortizovati u odnosu na ona koja su stečena u ranijoj životnoj dobi. Za razliku od fizičkog kapitala ljudski kapital gubi na vrednosti kada se ne koristi, na primer u slučaju nezaposlenosti. Takođe, ljudski kapital se dodatno stvara učenjem u okviru proizvodnog rada (learning by doing), dok se u proizvodnom korišćenju fizički kapital uvek troši, odnosno smanjuje (Dubravčić, 2007). Otuda se upravo u Bolonjskom procesu ističe značaj usmerenosti na zapošljivost pojedinaca. Pored pitanja finansiranja visokog obrazovanja primetna je istaknuta uloga ekonomskih aspekata koji sve više prodiru u obrazovni proces i utiču na redefinisanje ishoda obrazovanja. 
U okviru pristupa trošak-korist (cost-benefit analysis) tehnike koje su se koristile prilikom procene isplativosti ulaganja u fizički kapital bile su primenjene i na rashode uložene u obrazovanje kao investiciju kako bi se izračunala profitabilnost (Pastuović, 2012). Ovakav pristup omogućava poređenje isplativosti različitih materijalnih $\mathrm{i}$ nematerijalnih investicija $\mathrm{i}$ odabir najisplativije. U tom kontekstu Pastuović (2012) ukazuje na značaj isticanja razlika u isplativosti kada je reč o različitim nivoima obrazovanja. Kao najisplativije ističe se ulaganje u osnovno obrazovanje, kao i činjenica da je ulaganje u obrazovanje isplativije pojedincu nego društvu. Istovremeno ukazuje se na neopravdanost pojave da se u analizama isplativosti pojedinih nivoa i vrsta obrazovanja po pravilu ispušta predškolsko vaspitanje i obrazovanje iz razloga što ono nije deo formalnog školskog sistema. Pastuović (2012: 198) naglašava i činjenicu da, iako navodno nije roba, visoko obrazovanje to jeste iz razloga što se vrednuje na tržištu rada, zbog čega je individualni povrat ulaganja u visoko obrazovanje veći nego društveni. Dodatno, visoko obrazovana populacija ima najveće prosečne zarade, najzapošljivija je, najduže ostaje radno aktivna i ostvaruje osim materijalnih i najviše nematerijalnih koristi od obrazovanja.

U okviru proučavanja značaja univerziteta u cilju odgovaranja kompleksnom i promenjivom okruženju u literaturi se (Mujić i Legčević, 2008) ističe značaj kreiranja programa koji će zajednice, lokalne, regionalne pa i državu u celini razvijati u zajednice sposobnosti. Reč je o tome da se ukazuje na to da bi restrukturirani studijski programi trebalo da se usmeravaju na sadržaje u okviru kojih bi se studenti upoznavali s važnim odrednicama poslovnog uspeha i neuspeha u poslovanju, a za koje danas $u$ 
svetu postoje različiti nazivi: intelektualni potencijal, ljudski kapital, upravljanje znanjem, nevidljiva imovina.

\section{MERENJE I EFEKTI LJUDSKOG KAPITALA}

Bez obzira na činjenicu da se koncept ljudskog kapitala razvio u oblasti ekonomije, na njega se u današnje vreme pozivaju autori iz različitih naučnih disciplina $u$ procesu tumačenja društvenih fenomena $\mathrm{i}$ procesa, između ostalog, i obrazovanja (Spasenović, 2015). Odnos između obrazovanja i tržišta rada dugo je predmet brojnih istraživanja, a upravo model ljudskog kapitala može da se posmatra kao osnova povezivanja ovih elemenata (Belfield, 2000, prema Bečić, 2014: 215). Pri tome, znanje predstavlja ključnu odrednicu koncepta ljudskog kapitala. Znanje je skup ideja, iskustava, intuicija i veština koje se koriste u kreiranju nove vrednosti. Cilj je usmeriti znanje ka povećanju produktivnosti. Ispostavilo se da ulaganje $u$ znanje $u$ savremenim uslovima privređivanja označava najisplativiju investiciju, a da najrazvijenije zemlje sveta jesu one koje imaju visoko učešće izdataka na ime obrazovanja u strukturi bruto domaćeg proizvoda (Cvetanović i Despotović, 2014). Složenost problema vezanih za ljudski kapital, između ostalog, ogleda se i u merenju ljudskog kapitala. U literaturi se (Oxley, Le \& Gibson, 2008) identifikuju tri generalna načina merenja ljudskog kapitala: pristup zasnovan na troškovima (engl. cost-based approach), pristup zasnovan na prihodima (engl. income-based approach) i pristup zasnovan na obrazovanju (engl. education-based approach). Pritom se ističe da za razliku od konvencionalnih pristupa koji mere kapital prema trošku ili prinosu, pristup zasnovan na obrazovanju procenjuje ljudski kapital na osnovu pokazatelja obrazovnih efekata. 
Stopa pismenosti definiše se tipično kao udeo stanovništva starijeg od 15 godina koji je u stanju da čita i napiše jednostavnu izjavu o svom svakodnevnom životu. Stopa pismenosti odraslih pruža značajne informacije o opštem obrazovnom statusu zemlje. Međutim, značajno je reći da definisana na ovaj način varijabla ljudskog kapitala ima svoja ograničenja. Budući da opismenjavanje nije objektivno i dosledno definisano u svim zemljama, ono stvara pristranosti u međunarodnim upoređivanjima. Još značajnija je činjenica da uprkos tome što reflektuje fundamentalnu komponentu ljudskog kapitala, stopa pismenosti izostavlja većinu elemenata koji prevazilaze elementarni nivo, kao što su računanje, logičko i analitičko rezonovanje i naučna i tehnološka znanja. Na taj način, stopa pismenosti zanemaruje doprinos sposobnosti mišljenja na višim kognitivnim nivoima, što je čini korisnijim pokazateljem ljudskog kapitala u zemljama u kojima je stanovništvo manje obrazovano (Oxley, Le \& Gibson, 2008).

Stopa upisa u školu meri broj upisanih učenika na datom nivou u odnosu na stanovništvo starosne grupe koja bi, prema nacionalnom propisu ili običaju, trebalo da pohađa školu na tom nivou. Bruto stopa upisa koristi ukupan broj upisanih učenika na datom nivou, dok neto stopa upisa isključuje one učenike koji ne pripadaju određenoj starosnoj grupi. Dakle, stopa upisa meri trenutnu investiciju u ljudski kapital koja će se odraziti na zalihu ljudskog kapitala u budućnosti. Međutim, kao nedostatak merenja ističe se da stope upisa ne mogu tačno da odražavaju buduće tokove ljudskog kapitala, a još manje trenutne tokove ili trenutne zalihe (Oxley, Le \& Gibson, 2008). Pozitivne korelacije između rasta i akumulacije kapitala potvrđene su na primarnom nivou za siromašne zemlje, na sekundarnom nivou za zemlje sa 
srednjim dohotkom i na višim nivoima za bogate zemlje, ali nije pronađena veza između rasta i ljudskog kapitala za objedinjeni uzorak.

Prosečne godine školovanja kao pokazatelj ima prednosti u odnosu na stopu pismenosti i stopu upisa u školu, budući da kvantifikuje akumulisana ulaganja u obrazovanje u trenutnoj radnoj snazi. Posmatrano u celini, pristup zasnovan na obrazovanju zasniva se na tome da su navedeni pokazatelji usko povezani s ulaganjem u obrazovanje $i$ da je ulaganje $u$ obrazovanje ključni element u stvaranju kapitala. Obrazovni pokazatelji jesu, dakle posrednici, a ne direktne mere ljudskog kapitala (Oxley, Le \& Gibson, 2008).

Pastuović (2012) ističe da koristi od ulaganja u ljudski kapital nisu samo ekonomske, već i neekonomske prirode, te da mogu da se posmatraju na različitim nivoima. Kada je reč o individualnom nivou, koristi uključuju povećanje zarade, zapošljivosti, društvenog ugleda, kao i veće zadovoljstvo pojedinca. $\mathrm{Na}$ organizacionom nivou korist podrazumeva povećanje konkurentnosti preduzeća, smanjenje sukoba u organizaciji i zadovoljstvo zaposlenih, dok na nivou države korist podrazumeva povećanje bruto društvenog proizvoda po stanovniku, međunarodnu ekonomsku kompetitivnost, kao i veći kvalitet života. Pastuović (2012) percipira kvalitet ljudskog kapitala na nivou Evropske unije kao potencijalno najveću prednost u odnosu na druge ekonomske velesile, a celoživotno učenje kao strategiju njegovog stalnog poboljšanja. Takav stav predstavlja široko razumevanje koncepta kvaliteta ljudskog kapitala iz razloga što obuhvata više činilaca, a ne samo obrazovanje, kao i raznovrsne efekte, a ne isključivo one ekonomske prirode. Dodatno, takvo razumevanje tog koncepta ukazuje i na tretiranje ulaganja u ljudski kapital, ne kao potrošnju, već kao investiciju s ekonomskim i neekonomskim povratom. Upravo zbog teže merljivosti 
neekonomskih koristi njihovo merenje često se zanemaruje (Pastuović, 2012). Otuda se ističe još jedan razlog veće vidljivosti ekonomskih koristi od obrazovanja koje podrazumevaju dominantnost ekonomskih motiva $\mathrm{u}$ hijerarhiji motiva. Međutim, danas je sve bogatija evidencija o pozitivnom delovanju obrazovanja na zdravlje, trajanje života, smrtnost dece, ljudska prava i političku stabilnost, kriminalitet i zaštitu okoline, kao i druge indikatore socijalnog blagostanja. Značajno je da se i ekonomskim i neekonomskim koristima od obrazovanja pristupi u okviru njihove uslovljenosti jer zbog povezanosti ekonomije i drugih društvenih podsistema, neekonomski efekti deluju i na ekonomske. Primer za to jeste kako pozitivno delovanje na zdravlje ljudi smanjuje rashode zdravstvenog sistema (Pastuović, 2012). Osim toga, isticanje neekonomske koristi ljudskog kapitala ima značajan uticaj za očuvanje humanističke dimenzije obrazovanja.

\section{KRITIKA KONCEPTA LJUDSKOG KAPITALA}

Kada je u pitanju koncept ljudskog kapitala, važno je reći da se u literaturi (Dubravčić, 2007) ukazuje na teško prihvatanje upotrebe pojma 'kapital', koji sadrži i neke vlasničke odnose, i u slučaju čoveka. Taj se pojam povezuje sa različitim oblicima zavisnosti, gde se čovek ili njegove obaveze mogu kupiti i prodati što je u civilizovanom svetu neprihvatljivo. Ljudski kapital se u mnogim elementima razlikuje od „,vlasničkog” kapitala koji uključuje i proizvodna sredstva, a koji se može otuđiti tržišnom transakcijom. Tako se umesto ljudskog kapitala niz godina koristio izraz „,vrednost čoveka”. Međutim, u današnje vreme pojam ljudskog kapitala ušao je u široku upotrebu, iako se to više odnosi na ekonomsku literaturu nego ne ekonomsku praksu (Dubravčić, 2007). Prilikom definisanja ljudskog kapitala 
u literaturi se (Sokić, 2008: 430) ukazuje i na to da je ljudski kapital ,,.. doslovno srastao sa svojim vlasnikom ...” uz objašnjenje da se ljudi ne mogu fizički odvojiti od znanja, sposobnosti ili zdravlja koje poseduju, kao što su odvojeni od fizičkog ili finansijskog kapitala.

Kada je reč o merenju ljudskog kapitala, u okviru oslanjanja na pokazatelje postignutog obrazovnog nivoa stanovništva veliki problem predstavlja nedovoljna informisanost o znanjima koja su stečena neformalnim obrazovanjem, kao i o veštinama stečenim iskustvom koje takođe mogu biti važna komponenta ljudskog kapitala (Šošić, 2003). Ističe se i problem razlika $u$ kvalitetu obrazovanja koji je posebno naglašen $u$ uslovima štednje na obrazovanju, dok $\mathrm{u}$ isto vreme raste broj osoba koje se školuju. Problem merenja kvaliteta obrazovanja i njegovog uticaja na nivo ljudskog kapitala rešava se direktnim merenjem veština i obrazovnih postignuća, odnosno standardizovanim međunarodnim testovima (Šošić, 2003: 442).

Pojedini autori (Spasenović, 2019) ukazuju na to da nije nužno tačna teza da ljudi ulažu u svoje obrazovanje da bi kasnije ostvarili veću zaradu. Kao primer navodi se izdvajanje sredstava za pohađanje nekih kurseva (fotografije, hortikulture) koje često nije rezultat namere za sticanje finansijcke koristi u budućnosti, već je podstaknuto autentičnim interesovanjem za neku oblast ili ličnim uživanjem u bavljenju određenim aktivnostima. Ukazuje se i na to da ne postoji opšteprihvaćena saglasnost sa idejom da se na ljude gleda kao na potencijalne izvore iz kojih se može izvući ekonomska dobit (Spasenović, 2019). Međutim, ekonomska perspektiva u razmatranju uloge i funkcije obrazovanja danas postala je dominantna $\mathrm{i}$ 
upravo se i dovodi u pitanje činjenica da se fokus stavlja na odnos između obrazovanja i ekonomske kompetitivnosti.

\section{ZAKLJUČNA RAZMATRANJA}

Obrazovanje u celini, a prvenstveno visokoškolsko obrazovanje, nalazi se sve više pod uticajem neoliberalne ideologije i procesa globalizacije. U tom okviru i odnos pedagogije prema drugim društvenohumanističkim naukama dobija sve veći značaj. Za razumevanje brojnih izazova pred kojima se nalazi proces obrazovanja neophodno je njegovo dovođenje u vezu sa ekonomskim aspektima koji imaju direktan uticaj ne samo u okviru finansiranja visokog obrazovanja, već i kao posledice redefinisanja kurikuluma, uvođenja novih obrazovnih sadržaja, kao i očekivanih novih kompetencija $\mathrm{i}$ ishoda obrazovanja. $\mathrm{U}$ tom kontekstu koncept ljudskog kapitala dobija na značaju prvenstveno u okvirima globalizacije obrazovanja i ekonomije zasnovane na znanju koja ukazuje na značaj razumevanja mesta i uloge obrazovanja u tom procesu. Proučavanje ekonomije obrazovanja predstavlja značajnu dimenziju neophodnu za holistički pristup visokoškolskom obrazovanju. Upravo brojne kritike upućene tržišnom konceptu obrazovanja ukazuju na značaj proučavanja uticaja ekonomskih aspekata obrazovanja koji sve više dobijuju na značaju. Za holistički pristup savremenom obrazovanju u celini, a prvenstveno visokoškolskom obrazovanju neophodno je razumevanje pedagogije kao nauke, njenih filozofskih osnova, ali isto tako ništa manji značaj nema ni dovođenje u vezu pedagogije sa savremenim društvenim dešavanjima. Iako se zalaže za čuvanje obrazovnih vrednosti, Bok (2005) ukazuje na to da je na savremenim univerzitetima neizbežno i pitanje ostvarivanja profita, pitanje kojim se tradicionalni univerziteti nisu bavili. Kao posledica masifikacije 
visokog obrazovanja univerziteti se takmiče jedni protiv drugih. Iako su im motivi različiti (privlačenje najboljih studenata, osvajanje Nobelove nagrade, poražavanje suparnika na terenu za fudbal), cilj im je isti, a to je akademski ugled ili prestiž.

Posledice uplitanja savremenih društvenih dešavanja $\mathrm{u}$ proces obrazovanja rezultiraju i sintagmom o ekonomizaciji visokog obrazovanja (Jovanović-Kranjec, 2013). U aktuelnom strateškom dokumentu o razvoju obrazovanja u Srbiji - Strategija razvoja obrazovanja u Srbiji do 2020. godine (Službeni glasnik RS, 107/2012: 8) - polazi se od toga da se misija sistema obrazovanja iskazuje u okviru svrhe postojanja obrazovanja sa stanovišta spoljašnjega sveta, to jest da se izražava u okviru ključne dugoročne uloge obrazovanja u ekonomskom, socijalnom, naučnotehnološkom, kulturnom i drugom razvoju društva u celini, kao i u razvoju stvaralačkih i radnih potencijala i kvaliteta života svakog pojedinačnog građanina. $U$ istom se dokumentu polazi od toga da se dalji razvoj proizvodnog sistema Republike Srbije mora ubrzano zasnivati na znanju, preduzetništvu obrazovane populacije, sopstvenim i transferisanim tehnološkim inovacijama, tržišnoj ekonomiji i međunarodnoj poslovnoj, tehničkoj i drugoj kooperaciji. Otuda se daje značaj „preduzetničkom univerzitetu”, pri čemu takav univerzitet i ,znanje za tržište rada” ne bi trebalo da budu ono ka čemu jedino treba da teže visokoškolske ustanove kada je reč o ishodima obrazovanja (Jovanović-Kranjec, 2013). U tom se okviru u literaturi (Baatjes, 2005, prema Jovanović-Kranjec 2013: 94) ističe da je vreme da univerzitetski radnici svojim znanjem i kompetencijama pomognu u redefinisanju ishoda obrazovanja. To zahteva više angažovanja intelektualaca, nastavnika, studenata i građanskog društva, kao i razvoj 
kritičke svesti kod svih građana. Konačno, sveobuhvatan pristup ovom fenomenu nije moguć bez interdisciplinarnog pristupa ovoj tematici. Pedagoški diskurs pretpostavlja da u okviru merenja ljudskog kapitala veći akcenat treba staviti na njegove neekonomske aspekte, kao i da obrazovanje ne može uvek da se svede na kvantitativne pokazatelje jer se time u značajnoj meri umanjuje značaj humanističke dimenzije obrazovanja.

\section{HIGHER EDUCATION FROM THE VIEWPOINT OF THE HUMAN CAPITAL CONCEPT}

\section{Abstract}

Within the study of the relationship between pedagogy and other sciences, traditionally the primary importance is given to the relationship of pedagogy and philosophy, sociology, psychology, and anthropology, as the sciences close by the subject and methodology. This paper starts from the assumption that the relationship between pedagogy and economics should not be neglected in modern conditions. Contemporary education faces many challenges and changes which are primarily conditioned by the process of globalization, as well as the influences of neoliberal ideology. The aim of the paper is to consider the importance of human capital as a theoretical approach in the context of studying the globalization of education, which increasingly gains the importance, especially in the context of the discipline of higher education. However, the increasing importance of economic aspects in education has also resulted in a number of negative criticisms. As a conclusion of the paper, it is emphasized that education in general and higher education in particular, is increasingly getting an approach from the economic perspective. Although this process is inevitable, primarily as a consequence of globalization, precisely in order to preserve the humanistic dimension of education, it is important to understand many challenges and changes, which face the process of higher education.

Key words: economics of education, higher education, human capital 


\section{REFERENCE}

Bečić, M. (2014). Značaj obrazovanja na tržištu rada prema ekonomskoj teoriji. Ekonomska misao i praksa, 1, 213-232.

Bok, D. (2005). Univerzitet na tržištu. Beograd: Clio.

Cvetanović, S., \& Despotović, D. (2014). Znanje kao komponenta ljudskog kapitala u modelima ekonomskog rasta. Škola biznisa, 1, 1-17.

Dubravčić, D. (2007). O ljudskom kapitalu - kritičke bilješke. Economic Trends \& Economic Policy, 17, 29-49.

Grandić, R. (2007). Prilozi uvodu u pedagogiju. Novi Sad: Savez pedagoških društava Vojvodine.

Jovanović-Kranjec, M. (2013). Ekonomizacija visokog obrazovanja u Republici Srbiji. Ekonomski horizonti. 15(1), 87-96.

Kutlača, Đ., Semenčenko, D., Mosurović, M. M., \& Mitrović, Z. (2011). Izazovi visokog obrazovanja na prostoru Zapadnog Balkana. U: V. Matejić (ur.), Tehnologija, kultura, razvoj (str. 17-26). Beograd: Udruženje „Tehnologija i društvo”, Institut „Mihajlo Pupin”; Subotica: Ekonomski fakultet.

Lissmann, K. P. (2008). Teorija neobrazovanosti: zablude društva znanja. Zagreb: Jesenski i Turk.

Milutinović, J. (2008). Ciljevi obrazovanja i učenja u svetlu dominantnih teorija vaspitanja 20. veka. Novi Sad: Savez pedagoških društava Vojvodine.

Mujić, N., \& Legčević, J. (2008). Razvoj ljudskog kapitala, novo bogatstvo nacije. Informatologia , 41(3), 196-202.

Oxley, L., Le, T., \& Gibson, J. (2008). Measuring human capital: Alternative methods and international evidence. Korean Economic Review, 24(2), 283-344.

Pastuović, N. (2012). Obrazovanje i razvoj. Zagreb: Institut za društvena istraživanja u Zagrebu, Učiteljski fakultet u Zagrebu.

Puljić, A. (2001). Pojam ekonomije kroz stoljeća. Ekonomski pregled, 52(56), 545-569.

Strategija razvoja obrazovanja u Srbiji do 2020. godine (2012). Službeni glasnik Republike Srbije - Prosvetni glasnik, Br. 107/2012. 
Sokić, S. (2008). Teorijska zasnovanost tržišta rada. Godišnjak FPN, 2, 429445.

Spasenović, V. (2019). Obrazovna politika globalni i lokalni procesi. Beograd: Institut za pedagogiju i andragogiju Filozofskog fakulteta Univerziteta u Beogradu.

Šošić, V. (2003). Premija za obrazovanje i ulaganja u ljudski kapital u Hrvatskoj. Financijska teorija i praksa, 27 (4), 439-455.

Šućur, Z. (2008). Ljudski i sociokulturni kapital siromašnih u Hrvatskoj. U: J. Kregar, G. Flego, \& S. Ravlić (ur.), Hrvatska: kako sada dalje (str. 183-214). Zagreb: Pravni fakultet Sveučilišta u Zagrebu i Centar za demokraciju i pravo Miko Tripalo. 